\title{
A SINTAXE DA VIOLÊNCIA ENTRE HEGEL E MARX ${ }^{1}$
}

Vittorio MORFINO2

- RESUMO: Trata-se de investigar a tese marxiana acerca do papel da violência na história, tal como enunciada em O Capital, analisando sua sintaxe de matriz hegeliana e o modo como Engels articula tal tese, para então defender uma interpretação não-teleológica da violência, segundo a qual esta apresenta uma pluralidade de formas, um caráter totalmente difuso e uma pesada materialidade.

- PALAVRAS-CHAVE: Marx; violência; história; Hegel; teleologia.

\section{A parteira da história}

Há uma célebre expressão de Marx a propósito da violência que pode constituir um bom ponto de partida para tentar descrever sua sintaxe: no ponto culminante do capítulo 24 de 0 Capital, dedicado como se sabe à acumulação primitiva, Marx exclama que "A violência [Gewalt] é a parteira [Geburtshelfer] de toda velha sociedade que traz uma nova em suas entranhas. Ela mesma é uma potência [Potenz] econômica" (DK, p. 779 / 864 [trad. modificada]). ${ }^{3}$ Justamente porque se encontra na culminância do capítulo sobre a acumulação primitiva, ela parece nos dar a chave de leitura, o sentido e o resumo conceitual da pluralidade de histórias ali descritas. É realmente assim? Sobre isto retornaremos mais adiante. Contentemo-nos

1 Tradução: Herivelto P. de Souza.

2 Università degli studi di Milano - Bicocca. Artigo recebido em 08/08 e aprovado em 11/08.

3 NT: Para a referência das citações, o primeiro número de página refere-se è edição original, enquanto o segundo, quando disponível, é da tradução retirada da edição brasileira indicada na bibliografia. Quando necessário, tal tradução foi modificada, sendo devidamente indicado. 
por enquanto em analisar mais de perto a proposição marxiana. O que a metáfora usada indica? 1) a violência é uma potência econômica, mas marginal com respeito ao processo histórico; 2) a nova sociedade existe já no seio da velha e aguarda vir à luz. Se, para além do significado comum da metáfora, interrogamos o uso que dela fez a tradição filosófica, encontramos que a metáfora da gravidez está no centro da monadologia leibniziana e da concepção de temporalidade que ela designa: "o presente está prenhe do futuro" (GP, p. 610 / 65), exclama Leibniz no parágrafo 22 da Monadologia, "o presente está prenhe do futuro; o futuro poderia ser lido no passado" (GP, p. 604 / 160), acrescenta no parágrafo 13 dos Princípios da natureza e da graça. A metáfora designa o modo ineludível através do qual os estados de cada mônada se sucedem, comandados por uma lex seriei que é, em virtude da harmonia pré-estabelecida, a lei mesma da História e do seu Progresso. A proposição marxiana parece, assim, indicar um desenvolvimento linear do tempo histórico no qual uma lex seriei governa a transição de uma sociedade a uma outra escandindo os tempos da aparição da violência. Como é sabido, Engels dedicou alguns capítulos do Anti-Dühring à definição do papel da violência da história, papel que ele encontra perfeitamente sintetizado pela proposição marxiana. Com o escopo de melhor colocar em luz os enjeux teóricos desta questão, pretendo demonstrar que tal concepção de violência é comandada por uma sintaxe conceitual hegeliana, cuja estrutura lógica pode ser localizada em dois capítulos fundamentais da Grande lógica, e a dialética histórica em algumas passagens decisivas da filosofia do direito e da história.

\section{A violência na "Realidade" [Wirklichkeit]}

O primeiro dos dois lugares teóricos nos quais Hegel enfrenta a questão da violência, da Gewalt, é a terceira seção da Lógica da essência, a Wirklichkeit, onde a lógica binária produzida pela dialetização das categorias da tradição metafísica tende, enfim, a alcançar a unidade do conceito. Aqui, justamente sobre o umbral do conceito, no Zwischen entre reino da necessidade e reino da liberdade, aparece a primeira ocorrência significativa do termo Gewalt na dialética da causalidade, um wirken que pressupõe uma alteridade, um extrínseco. A causa age sobre si mesma assim como age sobre um outro, que aparece dessa maneira como substância passiva: em primeiro lugar, ela retira o ser-outro daquela e nela retorna em si, e, em segundo lugar, coloca este seu retorno em si como uma determinidade, ou seja, a determina. A substância passiva tem, portanto, uma natureza dúplice, uma vez que, de uma parte é um pressuposto independente, uma alteridade, e de outra parte é idêntica à causalidade agente. 
É neste nível da dedução que Hegel insere o conceito de Gewalt. A violência origina-se da ação da substância eficiente sobre a substância passiva, a qual sofre [leidet] violência. Leiamos a longa passagem que Hegel dedica à formulação deste conceito:

A violência é a manifestação da potência [Erscheinung der Macht], ou a potência como algo exterior [die Macht als Äußerliches]. Mas a potência só é algo exterior na medida em que a substância causal no seu atuar, isto é, no pôr-se a si mesma, é ao mesmo tempo [zugleich] algo que pressupõe, isto é, ela põe-se a si mesma como um suprassumido [Aufgehobenes]. Por isso, inversamente, o fazer [Tun] da violência é igualmente um fazer da potência. Ele é apenas um outro pressuposto por si mesmo, sobre o qual atua a causa violenta [gewaltige Ursache]; seu efeito sobre este é uma relação negativa a si, ou a manifestação de si mesmo. O passivo é o autônomo [das Selbstständige], que é apenas um posto, um roto [Gebrochenes] em si mesmo, - uma efetividade [Wirklichkeit] que é condição, e precisamente a condição desde então em sua verdade, a saber, uma efetividade que é apenas uma possibilidade, ou inversamente um ser-em-si que é apenas a determinidade do ser-emsi, que é apenas passivo. Desse modo, àquele a quem acontece [geschieht] a violência, não é apenas possível praticar violência, mas ela tem também de ser-lhe praticada; o que tem poder [Gewalt] sobre o outro, só o tem porque é a potência dele próprio que assim se manifesta e manifesta o outro. Por meio da violência, a substância passiva é apenas posta como aquilo que ela é em verdade, verdade que, justamente porque ela é o simples positivo ou a substância imediata, é ser apenas um posto; o prévio [das Voraus] que ela é enquanto condição [Bedingung] é a aparência [Schein] da imediaticidade, a qual a causalidade eficiente [wirkende Causalität] remove dela. (WdL - I, pp. 405-406) ${ }^{4}$

A ação da potência, isto é, da substância agente sobre a substância passiva, é uma ação violenta, ação que, no entanto, incide sobre si, sobre aquela substância que é o pressuposto do seu agir e que, em si, é idêntica a este agir: é aquilo que torna possível o manifestar-se da ação ela mesma. Aquilo que aparece como violência exercida por um agente sobre um paciente é na realidade uma ilusão de ótica; na realidade, o agente nada faz a não ser retirar a imediaticidade do paciente (ou melhor, o paciente posto como pressuposto de sua ação) e revelar a pressuposta exterioridade e imediaticidade como algo posto pela potência: a violência é, em conclusão, o fenômeno da potência, através do qual a substância passiva torna-se aquilo que ela é desde sempre, aquilo a que ela foi, desde sempre, destinada.

4 NT: para a tradução de passagens da Ciência da lógica, feita a partir do original, contei com o valioso auxílio de Ricardo Ploch, sendo, contudo, de minha responsabilidade quaisquer problemas que eventualmente tenham permanecido. 
Assim Hegel conclui este giro de pensamentos:

Assim, por meio do exercício de uma outra violência, só é praticado à substância passiva o que lhe é de direito. [Der passiven Substanz wird daher durch die Einwirkung einer andern Gewalt nur ihr Recht angetan]. O que ela perde é aquela imediaticidade, a substancialidade que lhe é estranha. O que ela recebe como um estranho, a saber, sendo determinada como um ser-posto, é sua própria determinação [ihre eigene Bestimmung]. - Mas, sendo posta em seu ser-posto ou em sua própria determinação, ela não é suprassumida; pelo contrário, dessa maneira ela não faz senão juntar-se a si mesma, e assim há originariedade em seu ser determinado. - A substância passiva é, portanto, por um lado conservada [erhalten], ou posta pela substância ativa, a saber, na medida em que esta torna-se a si mesma um suprassumido [aufgehobenen]; - só que, por outro lado, é o fazer do próprio passivo juntar-se a si mesmo, e por conseguinte tornar-se originário e causa. O ser posto por um outro e o devir próprio são um e o mesmo [ein und daßelbe]. (WdL - I, p. 406)

A substância passiva obtém da violência aquilo que lhe aguarda: perde a imediaticidade e recebe a sua determinação enquanto ser posto. A substância passiva, então, em primeiro lugar, é posta pela substância ativa como ser posto em si, e "então recebe em si uma ação através da outra [substância]" (WdL - I, p. 406); mas, em segundo lugar, ela produz uma "reação contra a causa agente". Com a diferença, porém, que enquanto na causalidade determinada se distinguiam a causa que um indivíduo é da causa que um indivíduo tem, na ação e reação cada indivíduo é tanto causa quanto efeito. A ação e a reação não produzem, pois, o mau infinito do regresso e do progresso indeterminado da causalidade transitiva, mas um "agir recíproco infinito" que não é outro que a causalidade dobrada sobre si mesma, que abandona enfim a imperfeita metáfora geométrica da reta para assumir aquela perfeita do círculo. Assim, abre-se caminho à ação recíproca ["Wechselwirkung"] como causalidade mútua de substâncias que se pressupõem e se condicionam reciprocamente. Cada resíduo de imediaticidade é enfim removido (enquanto posto), e assim não estamos mais diante de substratos, mas de substâncias. A ação recíproca é a própria causalidade, o conceito de causalidade e a causalidade que alcançou o conceito, é causa sui.

Tomemos agora distância do discurso hegeliano para observar de longe sua estratégia. Para que se torne possível o salto do reino da necessidade para o reino da liberdade, da substância ao sujeito, da obscuridade à transparência, à luz, é necessário que intervenha a instância da violência, que tem a função precisa de tolher esta obscuridade. Todavia, esta violência aparece como tal apenas a um olhar superficial, uma vez que ela na realidade se exerce apenas aparentemente sobre um pressuposto imediato, sobre uma obscura acidentalidade ["Zufälligkeit"]; na realidade esta contingência, esta obscuridade foi posta justamente pela luz do conceito para ser transformada 
em liberdade pela potência da necessidade. A luz se serve da obscuridade, dá-lhe dignidade, liberta-a da noite escura do insensato para inseri-la num desenho em claro-escuro do mundo que gradativamente deixa aparecer uma escala de determinidades: violência é o traço negro sobre a folha branca, violência apenas aparente, porque através dela a folha se nobilita, devém aquilo que era destinada a ser: desenho, sentido. Agora, se levarmos em consideração os efeitos implícitos do discurso hegeliano sobre a causalidade, tomado em sua estratégia englobante, emerge o fato de que o vir à luz do sentido é possível apenas com uma violência que, no entanto, é apenas aparente. Em resumo: 1) a violência é necessária; 2) a violência não é real, não é wirklich, não só pelo fato de que não é ela a atuar, wirken, e a produzir um efeito, Wirkung, ou seja, não é o motor do processo, mas também porque seu acontecer é o efeito de uma ilusão de ótica produzida pelo último nível da lógica binária das categorias metafísicas ["Wirkung und Gegenwirkung"], ilusão de uma dualidade que se resolverá na unidade da ideia.

\section{A violência na "Teleologia"}

Sigamos ao segundo lugar teórico. Como na lógica objetiva, também na lógica subjetiva o termo violência aparece, na diacronia do sistema, em um lugar crucial do ponto de vista estratégico: ele é um sinal direcional sobre a estrada que leva da teleologia à Ideia. Tal como na Wirklichkeit, na lógica objetiva a violência também aparece sobre um umbral, no Zwischen entre objetividade e subjetividade, ou, melhor ainda, sobre a limitação desta dualidade, antes que ela seja superada e retomada em uma unidade superior, o conceito adequado. Assim, é ainda no ponto de passagem entre objeto e sujeito, no ponto no qual a objetividade ergue-se ao seu mais alto nível, a teleologia, e logo antes de se tornar subjetividade, ideia, que a violência aparece no cenário predisposto pela sintaxe conceitual de Hegel.

A teleologia emerge em Hegel a partir da conhecida dialética entre mecanicismo e finalismo: a positividade do finalismo reside na unidade essencial, enquanto a negatividade está na imposição desta unidade essencial, de modo tão extrínseco e acidental que se torna preferível a acidentalidade imune da tautologia mecanicista. A via para superar o lado negativo do finalismo foi aberta por Kant:

Um dos grandes méritos de Kant com respeito à filosofia consiste na distinção por ele estabelecida entre finalidade relativa ou externa e finalidade interna [innerer Zweckmäßigkeit]; com esta última ele abriu o caminho ao conceito da vida [Begriff des Lebens], à ideia, e com isso elevou positivamente a filosofia por sobre as determinações reflexivas e do mundo relativo da metafísica. (WdL - II, p. 156) 
O que Hegel recusa da posição kantiana é o fato dele não colocar o único problema realmente filosófico, que consiste no se questionar "qual dos dois princípios tem verdade em si e por si" (WdL - II, p. 158). Trata-se então, segundo Hegel, de retomar a intuição kantiana e de levá-la até suas últimas consequências; trata-se, enfim, de trair e dar verdade ao empreendimento kantiano pensando novamente a metafísica como ciência, mas não mais com a ingenuidade dogmática de um Wolff ou de um Mendelssohn, e sim através do duro exercício do transcendental.

Estabelecido o primado da finalidade interna, Hegel passa a analisar os momentos singulares através dos quais ele deduz o conceito especulativo da teleologia:

a) A finalidade subjetiva. A finalidade é o conceito subjetivo entendido como esforço ou impulso a se tornar exterior, a pôr-se como exterioridade. Ela tem uma analogia como o conceito de força, entretanto é uma força que se autopropulsiona em direção ao tornar extrínseco, e tem uma analogia com o conceito de causa, mas é uma causa que é causa de si mesma, ou cujo efeito é imediatamente a causa. A finalidade é um subjetivo e a sua atividade se endereça contra uma objetividade exterior: ela tem, de fato, diante de si um mundo objetivo mecânico e químico, ao qual a sua atividade se refere como a algo já existente. Deste modo, Hegel determina a dialética da finalidade: "o movimento da finalidade pode portanto ser expresso assim, que ele procede ao suprimir sua pressuposição [Voraussetzung], isto é, a imediaticidade do objeto [Unmittelbarkeit des Objekts], e ao pô-lo como determinado pelo conceito" (WdL - II, p. 161).

b) $\mathrm{O}$ meio. Na finalidade é posto um interno e pressuposto um mundo exterior totalmente indiferente com respeito às determinações do fim. Hegel mostra como, dado este quadro conceitual, o fim, para ser conduzido a termo, precisa de um meio, que é uma existência externa que serve como termo médio: "A finitude do fim - escreve Hegel - consiste, pois, nisto: que o seu determinar em geral é externo a si mesmo e que por isso o seu primeiro determinar, como vimos, decompõe-se em um pôr e em um pressupor [in ein Setzen und in ein Voraussetzen]" (WdL - II, p. 162). Em outras palavras, Hegel sublinha como nesta relação o conceito e a objetividade se encontram coligados no meio apenas de maneira extrínseca, enquanto este é um objeto mecânico. Todavia, o meio resulta absolutamente penetrável ao fim, e é suscetível de tal comunicação de sentido apenas enquanto é idêntico ao fim. 
c) O fim realizado. O fim operante no seu meio não deve, então, determinar o objeto imediato como um extrínseco; e este deve fundir-se por si mesmo na unidade do conceito. Em outras palavras, a atividade exterior do fim através do meio deve suprimir a si mesma: "o porte [Verhalten] negativo da atividade teleológica frente ao objeto não é, por isto, extrínseco, mas é a mudança e a transição [Veränderung und Übergang] que a objetividade em si mesma realiza nele" (WdL - II, p. 165).

Neste contexto, Hegel determina a violência como o efeito da ação do fim sobre o objeto através do meio:

Que o fim se refira imediatamente a um objeto e faça deste um meio, tal como que o fim determine um outro por meio deste, pode ser considerado como violência [kann als Gewalt betrachtet werden], na medida em que o fim parece ser de uma natureza bem diferente da do objeto, e os dois objetos são, um frente ao outro, totalidades autônomas. Mas que o fim se ponha na relação mediata com o objeto, inserindo entre si e este um outro objeto, pode ser visto como a astúcia da razão [List der Vernunft]. A finitude da racionalidade tem, como já foi notado, este lado, o de que o fim se relaciona com a pressuposição, quer dizer, com a exterioridade do objeto. (WdL II, pp. 165-166)

A atividade é, então, o suprimir-se da aparência da exterioridade, um suprimir-se que pode aparecer como violência só se se considera o fim, o meio e o objeto exterior sobre o qual se exerce o fim como alteridades não mediáveis. Na realidade, o fim realizado revela-se como o ponto que comanda a dialética destes três momentos, que pertencem ao realizar-se do conceito: "O processo teleológico é tradução [Übersetzung] do conceito, que existe distintamente como conceito, na objetividade; vê-se que este traduzir em um pressuposto outro é o fundir-se do conceito consigo mesmo através de si mesmo" (WdL - II, p. 167).

Então, conclui Hegel, "pode-se dizer da atividade teleológica que nela o final é o início, a consequência é o princípio, o efeito é a causa, que ela é um tornar-se do que se tornou" (WdL - II, p. 167), e que assim a violência, como na dialética da Wechselwirkung, nada mais é que a ilusão de uma opacidade que foi colocada como tal para ser conduzida à transparência. O fim realizado comanda do ponto final do processo os movimentos do fim subjetivo, do meio e do objeto, servindo-lhes de peça sobre um tabuleiro de xadrez para levar a termo a própria estratégia: a violência não é senão um efeito ótico de quem observa de um ponto de vista limitado (neste sentido, é sintomática a expressão hegeliana "[...] kann als Gewalt betrachtet werden"), de quem olha para o finito sem considerar a unidade do processo, que é inteiramente 
permeado pelo conceito. Querendo nomear o sujeito deste olhar a partir do exterior, que apreende a violência no finito, sem penetrar a racionalidade englobante em que ela está inserida, poder-se-ia individuá-lo em uma faculdade, o intelecto, que mantém fixas as finitudes, sem penetrar sua vital relação com o infinito.

Todavia, um ponto da argumentação hegeliana ainda deve ser ressaltado, e é o aparecimento na cena teórica, no meio da redefinição hegeliana do conceito de finalidade, de uma expressão, List der Venunft, que pertence a todo um outro âmbito do sistema, ou seja, ao espírito objetivo, à filosofia da história. A astúcia da razão é o nome que Hegel dá à estratégia da razão na história, ao seu modo de utilizar os instintos, as paixões, os desejos e as empresas dos indivíduos para realizar o próprio plano universal, deixando então que estes indivíduos mesmos caiam como "cascas vazias". O que Hegel constrói na teleologia é a estrutura lógico-ontológica da historicidade, na qual a violência, como veremos em modo mais analítico, é sempre exercida sobre aquilo que não tem mais realidade, vida, e portanto é eliminado como algo de inessencial ao processo.

\section{A violência na Filosofia do Direito}

A estrutura conceitual intemporal da Grande Lógica comanda a dialética histórica da violência. Nos Princípios da filosofia do direito a violência ocupa o espaço teórico de um umbral, aquele entre o Estado e a história do mundo: $:^{5}$ esta aparece como Krieg no tratamento do direito público externo, onde Hegel define teoricamente a natureza das relações entre os Estados independentes. Os Estados se encontram um diante do outro em situação semelhante à dos homens no estado de natureza configurado por Hobbes, com a diferença de que não há qualquer lex naturalis que possa ser tornada efetiva por um poder coercitivo super partes. Em outras palavras, segundo Hegel o projeto kantiano de uma paz perpétua, alcançável graças a uma confederação de Estados em condições de aplainar toda controvérsia, permanece sobre o plano do dever ser: "Não há pretores - conclui, de fato, Hegel - mas, quando muito, árbitros ou mediadores entres os Estados e da sua vontade dependem as contingentes arbitragens e mediações" (GPR, p. 269 / 303).

5 Na realidade, ela aparece também na origem dos Estados, como "o direito dos heróis [Heroenrecht] que fundam Estados" (Hegel, GPR, p. 274 / 311). 
Enquanto as vontades particulares dos Estados não encontram um acordo, seus conflitos "só podem ser resolvidos pela guerra [Krieg]" (GPR, p. 268 / 304). Naturalmente, porém, a violência que se liberta nesta forma específica de Wechselwirkung não é acidental, mas deixa transparecer, através do caminho da história do mundo, os esplendores do conceito:

Nas relações entre si, os Estados comportam-se como particulares. Têm elas, por conseguinte, aquilo que há de mais mutável na particularidade, nas paixões, interesses, finalidades, talentos, virtudes, violências, injustiças e vícios, mas elevado à mais alta potência que possa assumir. Trata-se de um jogo em que o próprio organismo moral, a independência do Estado, está exposto ao acaso. Os princípios do espírito de cada povo ficam essencialmente limitados à causa da particularidade em que possuem a sua objetiva realidade e a consciência de si enquanto indivíduos existentes. Por isso os seus destinos, os seus atos nas recíprocas relações constituem a manifestação fenomênica da dialética destes espíritos enquanto finitos. É em tal dialética que se produz o espírito universal, o espírito do mundo enquanto ilimitado, e é ele que exerce, ao mesmo tempo, sobre esses espíritos o seu direito (que é o direito supremo) na história do mundo como tribunal do mundo. (GPR, pp. 270-271 / 306-307)

Do obscuro mar da Wechselwirkung das paixões, dos interesses, dos vícios, das virtudes e das violências subjetivas transparece a luz do conceito: a história do mundo não é, de fato, o "simples juízo da força, quer dizer, da necessidade abstrata e irracional de um destino cego [blinde Schicksal]" (GPR, p. 271 / 307), mas o desenvolver-se da autoconsciência e da liberdade do espírito: "A história do espírito é a sua ação [seine Tat], pois reside inteiramente no que faz e age [Tat]; é fazer de si mesma, e isso na medida em que é espírito, o objeto da sua consciência, conceber-se a si mesma ao compreender-se" (GPR, p. 271 / 307).

Os Estados, os povos e os indivíduos são conscientes do grau de evolução do espírito do qual são portadores, e ao mesmo tempo são instrumentos e membros inconscientes do trabalho do espírito, que elabora através deles a transição a seu grau superior:

A justiça e a virtude, a violência, o vício, o talento, a ação, as grandes e pequenas paixões, o crime e a inocência, o esplendor da vida individual e coletiva, a independência, a felicidade e a desgraça dos Estados e dos indivíduos, é no domínio da consciência real imediata que têm definidos o seu significado e o seu valor, nele encontram o seu juízo e sua justiça, embora incompletos. A história universal está fora destes pontos de vista. Nela adquire um direito absoluto o momento da ideia do espírito universal que é a sua atual expressão; o respectivo povo e as suas ações aí obtêm realização, felicidade e glória. (GPR, pp. 272-273 / 309)

A história é a configuração do espírito na forma do acontecer, da realidade natural imediata: ao povo, a quem cabe um princípio natural imediato, "fica com a missão de aplicá-lo no decorrer do progresso [Fortgang] e na 
consciência de si do espírito universal [Weltgeist] que se desenvolve" (GPR, p. 273 / 309). Este povo é, na história do mundo, para tal época, o povo dominante, e pode fazer a época apenas uma vez, ainda que de modo total:

Em face do direito absoluto que lhe cabe como representante do grau atual de desenvolvimento [gegenwärtigen Entwicklungstufe] do espírito do mundo, nenhum direito têm os outros povos que, tais como aqueles que já representaram uma época passada [deren Epoche vorbei ist], nada são na história universal. (GPR, p. 273 / 309)

A Gewalt da lógica se manifesta na forma histórica de Krieg. Esta se liberta contra os povos que obscurecem a transparência do espírito de uma época. O que sofre violência recebe aquilo que lhe aguarda no desenrolarse do processo, como escreve Hegel na sua Lógica objetiva, "Der passiven Substanz wird daher durch die Einwirkung einer andern Gewalt nur ihr Recht angethan", vê escrita no seu corpo, como no célebre conto de Kafka, a sentença do Weltgericht. Mas, no fundo, o ponto de vista que apreende a violência é ainda limitado, ilusório, como escreve Hegel na lógica subjetiva, “...kann als Gewalt betrachtet werden", mas por uma faculdade como o intelecto que quer substancializar o momento particular sem inseri-lo no quadro da totalidade: os povos que sofrem violência são, de fato, privados de espírito, não contemporâneos, dotados de uma forma de existência fantasmática, priva de vida, sobrevivências de um Zeitgeist já em ocaso na história do mundo.

Estes, ao sofrer violência, não fazem outra coisa que tornar executiva a sentença do tribunal da história em modo não diferente de como a pena reafirma o direito negado. Escreve Hegel nas Grundlinien:

§100. A pena com que se aflige o criminoso não é apenas justa em si; justa que é, é também o ser em si da vontade do criminoso, um ser-aí [Dasein] da sua liberdade, o seu direito $[R e c h t]$. E é preciso acrescentar que, em relação ao próprio criminoso, constitui ela um direito, está já implicada na sua vontade existente, no seu ato. Porque vem de um ser de razão, este ato implica a universalidade que por si mesmo o criminoso reconheceu e à qual se deve submeter como ao seu próprio direito. (GPR, p. 155 / 89 [tradução modificada])

\section{A violência no Anti-Dühring}

O percurso por dentro destes textos trouxe à luz como a violência, na sintaxe conceitual hegeliana, constitui um momento necessário do devirsujeito da substância. A retomada da dialética hegeliana por Engels, mesmo sendo invertida, isto é, fundada não mais sobre a ideia, mas sobre o econômico, mantém inalterada a sintaxe conceitual que regula a passagem da necessidade à liberdade, da Wechselwirkung da natureza e da história até 
a transparência finalmente realizada no comunismo. ${ }^{6}$ Isto emerge de modo paradigmático em um texto de enorme importância histórica dentro da tradição marxista, o Anti-Dühring de Friedrich Engels. Nesta obra, uma verdadeira enciclopédia do socialismo, encontra espaço dentro da segunda seção ("Economia política") uma "Teoria da violência" que será, em seguida, reelaborada em um texto autônomo, e publicada postumamente com o título de O papel da violência na história.

As teses engelsianas sobre a violência são construídas em polêmica com a afirmação de Eugen Dühring, expoente de destaque da social-democracia alemã, segundo o qual "a configuração das relações políticas é historicamente fundamental, e as dependências econômicas nada mais são que [...] fatos de segunda ordem" (AD, p. 147 / 137). O fato primitivo é, segundo Dühring, "a violência política [politische Gewalt] imediata, e não [o] poder econômico indireto" ( $A D$, p. 147 / 137 [tradução modificada]), e, por consequência, "é evidente que os fenômenos econômicos têm a sua raiz em causas políticas e, mais concretamente, na violência" ( $A D$, p. 148 / 137). Dühring traz como símbolo do primado da violência política sobre o econômico o relacionamento entre Robinson Crusoé e Sexta-Feira. Contra este exemplo, Engels mostra como nenhuma violência pode ser considerada como causa primeira, mas como, na realidade, ela pressupõe condições para ser exercida. No caso de Crusoé e Sexta-Feira, não é suficiente que o primeiro possua uma espada para colocar o segundo ao seu serviço; para poder servir-se de um escravo é necessário possuir os instrumentos e os objetos para o trabalho do escravo e os meios necessários para seu sustento: logo, a violência é apenas o meio, enquanto o fim é a vantagem econômica.

A violência política não pode ser considerada como um fato primitivo, mas deve ser historicizada: Engels mostra que a violência não é "um simples ato de vontade", mas pressupõe condições de existência determinadas, como a produção de armas, cujo nível técnico é decisivo na resolução de conflitos:

A vitória da violência repousa sobre a produção de armas, e esta, por sua vez, repousa sobre a produção em geral, e, portanto sobre a 'potência [Macht] econômica', sobre a 'situação econômica', sobre os meios materiais que estão à disposição da violência. ( $A D$, p. 154 / 145. [tradução modificada])

O primeiro movimento do discurso engelsiano consiste, então, em uma relativização historicista da violência, de causa primeira metafísica a instrumento determinado por fatores sócio-econômicos. Engels toma como

6 Para uma demonstração analítica desta tese, cf. "Causa sui o Wechselwirkung: Engels tra Spinoza e Hegel"; in: AA. VV. Friedrich Engels cent'anni dopo. Ipotesi per un bilancio critico, a cura di Mario Cingoli. Milano: Teti, 1998, pp.120-147. 
exemplo a revolução da arte da guerra provocada pela introdução da pólvora e das armas de fogo no século XIV, que "não foi precisamente um ato de violência [Gewalttat], mas um progresso industrial e, portanto, um progresso econômico" (AD, p. 155 / 146). E Engels conclui que "até que ponto a tática da guerra depende atualmente do estado da produção e dos meios de comunicação do país, que o exército tem em sua retaguarda, é coisa que qualquer suboficial, por pouco instruído, poderá explicar ao Sr. Dühring" (AD, p. 159 / 149).

O segundo movimento consiste em uma precisa definição do "papel da violência na história com relação ao desenvolvimento econômico" ( $A D$, p. 169 / 160. [tradução modificada]):

Em primeiro lugar, a força política se baseia, sempre, desde as suas origens, numa função econômica, social, e ela se intensifica na medida em que, com a dissolução da primitiva comunidade, os indivíduos se convertem em produtores privados, aprofundando-se mais ainda a sua separação dos que dirigem as funções sociais coletivas. Em segundo lugar, assim que a força política adquire existência própria em relação à sociedade, convertendo-se os seus detentores de servidores em seus donos, pode essa força operar em dois sentidos diferentes. Às vezes atua no sentido e com a orientação das leis que regem o desenvolvimento econômico. Neste caso, não há nenhuma discrepância entre os dois fatores, e a violência não faz mais que acelerar o processo econômico. Outras vezes, entretanto, a força política opera em sentido contrário e, nestes casos, acaba sempre por sucumbir, com raras exceções, frente ao vigor da evolução econômica. (AD, pp. 169-170 / 160 [tradução modificada])

Da Wechselwirkung dos fatores que constituem a história da sociedade humana emerge de modo irrefreável o telos do desenvolvimento econômico (assim como, em Hegel, emerge o telos do desenvolvimento da Ideia). A violência pode, assim, acelerar ou frear o curso do desenvolvimento histórico, mas nunca mudá-lo. E, no entanto, do discurso engelsiano emerge um matiz ulterior que o aproxima de maneira ainda mais radical da teoria hegeliana da violência:

Para o Sr. Dühring, a violência é a maldade absoluta. O primeiro ato de violência [Gewaltakt] é, para ele, o pecado original, reduzindo-se todo o seu arrazoado a um sermão jeremíaco sobre o contágio do pecado original em todos os fatos históricos, e sobre a infame deturpação de todas as leis naturais e sociais por essa potência diabólica [Teufelsmacht], que é a violência. Sabemos nós que a violência desempenha também, na história, um papel muito diferente, um papel revolucionário [eine revolutionäre Rolle]; sabemos que ela é, também, para usar uma expressão de Marx, a parteira de toda a sociedade antiga, que traz em suas entranhas uma outra nova: que é ela um instrumento por meio do qual se faz efetiva a dinâmica social, fazendo saltar aos pedaços as formas políticas fossilizadas e mortas. Mas, a respeito de tal aspecto, nada nos diz o Sr. Dühring. (AD, p. 171 / 161. [tradução modificada]) 
Como em Hegel, a violência é o fenômeno da potência, da ação exercida pelo que é vital sobre aquilo que está morto e enrijecido; sobre aquilo que, mesmo tendo uma existência positiva [Realität], não tem mais uma realidade efetiva [Wirklichkeit], sendo uma sobrevivência de uma época já declinada: a violência em Engels é a astúcia do econômico que destrói o poder político quando este se opõe ao desenvolvimento das forças produtivas, forma de destruição cujo paradigma é dado pela revolução francesa. A revolução comunista, repetindo e radicalizando o movimento da revolução francesa, produzirá "o salto da humanidade do reino da necessidade para o reino da liberdade" (AD, p. 264 / 65).

\section{O papel da violência na ordem do discurso de Hegel e de Engels}

Mostrou-se como a passagem da substância ao sujeito, do reino da necessidade àquele da liberdade, é possível apenas sob a condição de que o momento da violência intervenha. O que é, enfim, a violência? Retomemos brevemente os resultados coletados no nosso itinerário hegeliano: a violência é, na "Wirklichkeit", o fenômeno da ação da potência sobre um pressuposto ou alteridade; na "Teleologie", o efeito da ação do fim subjetivo sobre um mundo objetivo através de um meio. Tal gramática conceitual faz com que a aparição histórica da violência sob forma de Krieg, na "Weltgeschichte", como ação do Estado dominante sobre os Estados dominados seja:

1) O efeito da ação do conceito, do logos, sobre uma alteridade que ele mesmo pôs como pressuposto necessário da sua ação;

2) A ilusão do finito produzida pela incapacidade do intelecto de apreender a totalidade do processo.

A necessidade da ação violenta sobre a passividade pressuposta desmaterializa os efeitos da violência. A primeira aparição do termo violência na lógica da essência coloca precisamente o ser-sempre-já da violência, a sua atemporalidade, que fará com que toda forma de violência histórica apareça como a esgotada repetição de uma ação sempre-já ocorrida. Como sustentava Ernst Bloch, a violência no sistema de Hegel é a violência que se estuda nos bancos de escola, uma violência que acontece sempre e não acontece nunca, justamente porque a contingência que a caracteriza é atravessada por uma necessidade superior: as coisas que sofrem violência recebem aquilo que merecem no desenrolar-se do processo. Nem mesmo por um instante Hegel se detém sobre aquilo que a violência destrói; sobre aquilo que é para sempre cancelado por sua ação, porque a ordem do discurso veta o desespero diante do abismo da dor, de uma perda brusca não 
recuperável pela dialética do processo, que a violência provoca. A violência é a ilusão do finito, como indica claramente a sua ocorrência na "Teleologie"; no fundo, nada mais é do que o sintoma de um reapropriar-se, da parte do conceito, de uma exterioridade, do fazer-se luz do conceito, em outras palavras, um sintoma da liberdade. Aquilo que é destruído havia sido posto para ser destruído, e a sua própria destruição é uma experiência que será conservada no caminho do espírito.

Se substituirmos o logos pelo econômico, se recolocarmos de pé a dialética que estava de cabeça para baixo, encontramos a sintaxe idêntica em Engels, sintaxe esta que produz uma série de efeitos de extrema importância:

1) A unidirecionalidade da violência, o seu ser indicador seguro da direção do processo histórico;

2) O acontecer pontual da violência, seu ser o epifenômeno de um salto de nível;

3) A sua desmaterialização, exercendo-se sobre aquilo que está morto e enrijecido.

Ora, nas célebres conclusões marxianas do capítulo 24 sobre a "expropriação dos expropriadores", parece poder-se delinear uma sintaxe deste gênero:

O modo capitalista de apropriar-se dos bens, decorrente do modo capitalista de produção, ou seja, a propriedade privada capitalista, é a primeira negação da propriedade privada individual, baseada no trabalho próprio. Mas a produção capitalista gera sua própria negação, com a fatalidade de um processo natural. É a negação da negação. Esta segunda negação não restabelece a propriedade privada, mas a propriedade individual tendo por fundamento a conquista da era capitalista: a cooperação e a posse comum do solo e dos meios de produção gerados pelo próprio trabalho. (DK, p. $791 / 876-877)$

A violência aqui é unidirecional, ela indica precisamente a direção do processo histórico; é pontual, aparece nos saltos de nível; é desmaterializada pelo olhar que sabe abraçar a totalidade do processo no seu duplo movimento de negação que conduz do feudalismo ao comunismo, da necessidade à liberdade.

\section{Dialética ou arqueologia da violência?}

Trata-se, agora, de se perguntar se esta dialética da violência que aparece tanto no conceito de dupla negação quanto na metafísica do parto é realmente a ossatura filosófica do capítulo 24, ou se ela constitui uma espécie de distorção deste capítulo. Em um escrito de 1982, publicado postuma- 
mente, Althusser opõe uma concepção teleológica e uma concepção aleatória do modo de produção, que estariam em ação nas obras econômicas de Marx. À primeira está, sem dúvida, ligado um conceito de violência comandado pela sintaxe hegeliana: o modo de produção feudal é grávido do modo de produção capitalista, este está contido em germe naquele (ainda Leibniz e o preformismo), e a violência aparece no momento do nascimento, ela ajuda o nascimento que é, de qualquer forma, inevitável. Mas, qual conceito de violência está ligado à segunda concepção?

No primeiro parágrafo Marx escreve: "A estrutura econômica da sociedade capitalista nasceu da estrutura econômica da sociedade feudal. A decomposição desta liberou elementos para a formação daquela" (DK, p. 743 / 828). A primeira proposição parece poder-se remeter a uma lógica teleológica e preformista; todavia a segunda lhe escapa: a dissolução liberou os elementos, mas estes não se encontram já combinados necessariamente, a sua combinação é aleatória. Como escreve Althusser em um manuscrito de 1966, intitulado Sur la genèse:

1) Os elementos definidos por Marx se 'combinam', eu prefiro dizer (para traduzir o termo Verbingung) se 'conjugam' 'constituindo-se' numa nova estrutura. Esta estrutura não pode ser pensada em seu surgimento como o efeito de uma filiação, mas como o efeito de uma conjunção. Esta Lógica nova nada tem a ver com a causalidade linear da filiação, nem com a causalidade 'dialética' hegeliana, que apenas enuncia em voz alta aquilo que contém implicitamente a lógica da causalidade linear. 2) Portanto, cada um dos elementos que se combinam na conjunção da nova estrutura (na espécie do capital-dinheiro acumulado, das forças de trabalho 'livres', isto é, despojadas de seus instrumentos de trabalho, das invenções técnicas) é, ele mesmo, enquanto tal, um produto, um efeito. O que é importante na demonstração de Marx é que esses três elementos não são produtos contemporâneos de uma só e mesma situação: dito de outra forma, não é o modo de produção feudal que, por si mesmo, e por uma finalidade providencial, engendra ao mesmo tempo os três elementos necessários para que a nova estrutura 'se constitua'. Cada um destes elementos tem sua própria 'história', ou sua própria genealogia [...]: as três genealogias são relativamente independentes. Vê-se mesmo Marx mostrar que um mesmo elemento (as forças de trabalhos 'livres') pode ser produzido como resultado por genealogias totalmente diferentes. Assim, as genealogias dos três elementos são independentes uma das outras, e independentes (na sua co-existência, na co-existência de seus resultados respectivos) da estrutura existente (o modo de produção feudal). O que exclui toda possibilidade de ressurgimento do mito da gênese: o modo de produção feudal não é o 'pai' do modo de produção capitalista no sentido de que este estaria, teria estado contido 'em germe' no primeiro.

7 Louis Althusser. "Sur la genèse", 22 septembre 1966. Arquivo Montag. ["1) les éléments définis par Marx se 'combinent', je préfère dire (pour traduire le terme de Verbindung) se 'conjoignent' en 'prenant' dans une structure nouvelle. Cette structure ne peut être pensée, dans son surgissement 
Se lemos o capítulo 24 segundo esta perspectiva, a violência perde os traços de unidirecionalidade, de pontualidade e de imaterialidade que the confere a sintaxe filosófica hegeliana, necessária Sexta-feira Santa especulativa na estrada que conduz ao espírito (ou ao comunismo), para reconquistar a pluralidade de formas, o caráter difuso e a materialidade de uma historicidade não dominada pelo ritmo de uma essência, mas por um policronismo fundamental.

1) Pluralidade de formas. O termo violência é a forma resumidora e genérica de uma pluralidade de processos reais que vai da conquista à escravização, do assassinato à rapina (cf. $D K$, p. 742 / 828). Não é o indicador unívoco e direcional de um processo de transição de uma sociedade à outra, que advém em um tempo qualquer. Esta dissolve algumas formas de existência da sociedade feudal liberando elementos que se conjugarão dando lugar à sociedade capitalista, mas nunca através de um modelo de causalidade simples e transitiva: o proletário inglês (e a localização do processo é já uma cautela metodológica contra filosofias compreensivas da violência) é o efeito de uma pluralidade de causas que de modo algum lhe continham antecipadamente (a dissolução das continuações feudais, o cercamento das terras comuns para o pasto das ovelhas, o furto dos bens eclesiásticos efeito da Reforma, o clearing of estates, isto é, a expulsão dos arrendatários das grandes propriedades), cada uma das quais deve ser analisada na sua temporalidade específica (por exemplo, na diferença entre a relativa instantaneidade do furto dos bens eclesiásticos e no clearing of estates na Alta Escócia e na Irlanda e o processo de longa duração da expropriação das terras comuns que vai do século XV ao XVIII, mesmo mudando de natureza da

comme l'effet d'une filiation, mais comme l'effet d'une conjonction. Cette Logique nouvelle n'a rien a avoir avec la causalité linéaire de la filiation ni avec la causalité 'dialectique' hegelienne, qui ne fait qu'énoncer à haute voix ce que contient implicitement la logique de la causalité linéaire. 2) Pourtant chacun des éléments qui viennent se combiner dans la conjonction de la nouvelle structure (en l'espèce du capital-argent accumulé, des forces de travail 'libres' c'est-à-dire dépouillées de leurs instruments de travail, des inventions techniques) est lui-même, en tant que tel, un produit, un effet. Ce qui est important dans la démonstration de Marx c'est que ces trois éléments ne sont pas les produits contemporains d'une seule et même situation: ce n'est pas, autrement dit, le mode de production féodal qui, à lui seul, et par une finalité providentielle, engendre en même temps les trois éléments nécessaires pour que 'prenne' la nouvelle structure. Chacun de ces éléments a sa propre 'histoire', ou sa propre généalogie [. ]: les trois généalogies sont relativement indépendantes. On voit même Marx montrer qu'un même élément (les forces de travail 'libres') peut être produit comme résultat par de généalogies tout à fait différentes. Donc les généalogies des trois éléments sont indépendantes les unes des autres, et indépendantes (dans leur coexistence, dans la co-existence de leur résultats respectifs) de la structure existante (le mode de production féodal). Ce qui exclut toute possibilité de résurgence du mythe de la genèse: le mode de production féodal n'est pas le 'père' du mode de production capitaliste au sens ou le second serait, aurait été contenu 'en germe' dans le premier. "] 
"violência individual" ao uso da "lei [como] veículo do roubo" (DK, p.752 / 838)). A violência adquire então um sentido apenas em uma história feita pelo futuro anterior, ex post, na qual a flutuação que precedeu a conjunção é aprisionada em um tempo linear e teleológico.

2) A difusão. A violência não é, de fato, pontual, não aparece para assinalar um salto de nível, age, porém, de modo totalmente difuso em diferentes níveis: na separação violenta dos produtos dos meios de produção (segundo modalidades e temporalidades diferentes, como dito), na legislação contra a vagabundagem que "por meio de um grotesco terrorismo legalizado" induzia a disciplina necessária "ao sistema de trabalho assalariado" (DK, p. 765 / 850-851) produzido por tal separação, e enfim na legislação "para 'regular' o salário, isto é, comprimi-lo dentro dos limites convenientes à produção de mais-valia, para prolongar a jornada de trabalho e para manter o próprio trabalhador num grau adequado de dependência" (DK, pp. 765766 / 851). Mas esta pluralidade de níveis não constitui uma Stufenfolge, uma série de degraus sucessivos burilada pela violência, mas antes um complexo entrelaçamento na qual às vezes a violência produz os efeitos previstos, enquanto outras vezes efeitos não esperados ocorrem e outras vezes ainda um perda seca sem qualquer efeito.

3) A materialidade. Nesta perspectiva a violência readquire toda a sua pesada materialidade, torna-se novamente visível nos corpos a dor da fome, da pobreza, do aprisionamento, do disciplinamento, do cansaço. Não um ilusório epifenômeno de um processo histórico que varre aquilo que está morto, mas um tecido plural, e penetrante em todos os níveis, da gênese e da estrutura do modo de produção capitalista (sem, obviamente, que a lógica da violência da estrutura seja pensada como telos da violência da gênese). Portanto, não uma dialética da violência, mas uma arqueologia da violência, capaz de individuar na complexa estratificação e diferenciações das violências historicamente determinadas a dor infligida a cada corpo singular. É assim que as páginas do capítulo 24 evocam "as habitações dos camponeses e as choupanas dos trabalhadores [...] violentamente demolidas ou abandonadas à decadência total" no processo de transformação dos campos em pastos de ovelhas (DK, p. 746 / 832), "a supressão dos conventos [que] enxotou os habitantes de suas terras, os quais passaram a engrossar o proletariado" (DK, p. 749 / 835), os colossais "roubos às terras do Estado" (DK, p. 751 / 837), as Bills of inclosures, ou seja, "a própria lei [como] o veículo do roubo das terras pertencentes ao povo" (DK, p. 752 / 838), o clearing of estates, isto é, "a chamada limpeza das propriedades, a qual consiste em varrer destas os seres humanos" (DK, p. 756 / 842); e ainda a legislação sanguinária sobre a vagabundagem contra uma grande massa de homens transformada em "mendigos, ladrões, vagabundos", o chicote, as correntes, 
a prisão, o ferro incandescente sobre a carne, o corte da orelha, as leis penais de exceção contra as coalizões dos operários, a barbárie e a atrocidade do sistema colonial, o furto de homens, as carestias provocadas pelas especulações, o assassinato, a rapina, os cortes sobre as cabeças de homens, mulheres e crianças. E estas páginas remetem a outras páginas extraordinárias, aquelas do capítulo 8, sobre a jornada de trabalho, onde a violência se manifesta como prolongamento indefinido do tempo de trabalho diário, como redução dos tempos para as refeições e para o repouso, como imposição do trabalho noturno e do sistema de turnos até nas suas formas extremas e inclusive incríveis (crianças feitas trabalhar por vários turnos consecutivamente): Marx torna quase tangível a fadiga inumana imposta pelo processo de produção aos corpos dos homens e ainda mais sobre os das crianças, fadiga inumana que provoca sofrimentos físicos e psíquicos, causa frequente de doenças e morte.

Dissemos arqueologia da violência, arqueologia capaz de mostrar como a violência pode produzir efeitos históricos (ou mesmo não produzi-los), porém nunca ostentar os títulos de nobreza do Sentido da história. Como escreve Benjamin na mais bela das suas Teses sobre a história, "nunca há um documento da cultura que não seja, ao mesmo tempo, um documento da barbárie [Es ist niemals ein Dokument der Kultur, ohne zugleich eis solches der Barbarei zu sein]" (ÜBG, p. 30 / 70). Mas o que podemos deduzir desta arqueologia sobre o plano de um discurso político sobre a violência? A política não pode ser enxertada em uma filosofia da história da qual é o êxito necessário, sem, no entanto, acabar sendo pensada como a irrupção messiânica da eternidade em um tempo privado de qualidade. Deve ser refutada a secularização de ambos os grandes modelos de temporalidade cristã, aquele de Paulo, segundo o qual Deus virá "como um ladrão à noite" e aquele de Gioacchino da Fiore, que parte em três a linha do tempo, nas épocas sucessivas da humanidade. A política é a intervenção na conjuntura, intervenção em um horizonte dominado por uma temporalidade plural cujo entrelaçamento oferece por vezes à virtude "a miraculosa ocasião" e por outras a torna completamente ineficaz. Tal intervenção deve ser pensada segundo o modelo maquiaveliano do centauro, metade homem e metade animal: isto significa que a intervenção política não pode elidir a questão da violência precisamente pelo fato de que a ordem sócio-política existente é sempre-já violenta e, no entanto, não pode jamais descarregar da violência o peso da dor que provoca, nem ter garantias sobre seu sentido. 
MORFINO, Vittorio. The syntax of violence between Hegel and Marx. Trans/Form/ Ação, (São Paulo), v.31(2), 2008, p. 19-37.

- ABSTRACT: The Marxian Thesis about the role of violence in History, as it is enunciated in The Capital, is investigated through an analysis of the Hegelian character of its syntax, and the way Engels develops it; a non-teleological interpretation of the thesis is then defended, one that understands that violence presents a plurality of forms, a pervasive character and a heavy materiality.

- KEYWORDS: Marx; violence; history; Hegel; teleology.

\section{Referências bibliográficas}

ALTHUSSER, Louis. "Sur la genèse", 22 Setembro 1966. Arquivo Montag.

BENJAMIN, Walter. (ÜBG) Über den Begriff der Geschichte; in: Sul concetto di storia. Torino: Einaudi, 1997. [In: LÖWY, Michael. Walter Benjamin: aviso de incêndio. Uma leitura das teses "Sobre o conceito de história". Trad. de Wanda N. C. Brant. Tradução das teses por Jeanne-Marie Gagnebin, Marcos Lutz Müller. São Paulo: Boitempo, 2005.]

ENGELS, Friedrich. (AD) Herrn Eugen Dührings Umwälzung der Wissenschaft, in: Marx Engels Werke, Bd. 20, 10. Auflage. Berlin: Dietz, 1990. [Edição brasileira: Anti-Dühring: filosofia, economia política, socialismo. 2. ed. Rio de Janeiro: Paz e Terra, 1979; e Do socialismo utópico ao socialismo científico. São Paulo: Moraes, 2003.]

HEGEL, G. W. F. (WdL - I) Wissenschaft der Logik, Erster Teil - Die objektive Logik (1812/1813), herausgegeben von F. Hogemann und W. Jaeschke, in: Gesammelte Werke, Bd. 11. Hamburg: Felix Meiner Verlag, 1978.

(WdL - II) Wissenschaft der Logik, Zweiter Band - Die subjekive Logik (1816), herausgegeben von F. Hogemann und W. Jaeschke, in: Gesammelte Werke, Bd. 12. Hamburg: Felix Meiner Verlag, 1978.

(GPR) Grudlinien der Philosophie des Rechts, in: Sämtliche Werke, Band VII, herausgegeben von G. Lasson. 4. Auflage. Stuttgart: Friedrich Fromman Verlag, 1964. [Edição brasileira: Princípios da filosofia do direito. Trad. de Orlando Vitorino. São Paulo: Martins Fontes, 1997.]

LEIBNIZ, G. W. (GP) Die Philosophischen Schriften, Bd. 6. Ed. C. J. Gerhardt. Hildesheim: Olms, 1965. [Edição brasileira: Os princípios da filosofia ditos A monadologia (Coleção Os Pensadores - Vol. XIX). Trad. de Marilena Chauí. São Paulo: Abril Cultural, 1974; e Princípios da natureza e da graça fundados na razão; in: Discurso de metafísica e outros textos. Trad. de Alexandre da Cruz Bonilha. São Paulo: Martins Fontes, 2004.]

MARX, Karl. (DK) Das Kapital, Erster Band; in: Marx Engels Werke, Bd. 23, 22. Auflage. Berlin: Dietz, 2005. [Edição brasileira: O Capital: crítica da economia política - livro I, volume 2. Trad. de Reginaldo Sant'Anna. 20. ed. Rio de Janeiro: Civilização Brasileira, 2005.] 